Andrew Davenport

\title{
Clinical guidelines for the protection of kidney function and prevention of acute kidney injury in the intensive care unit: common sense rather than magic bullets?
}

Received: 28 August 2009

Accepted: 1 September 2009

Published online: 17 November 2009

(C) Copyright jointly hold by Springer and ESICM 2009

This editorial refers to the article available at: doi:10.1007/s00134-009-1678-y.

\section{A. Davenport $(\varangle)$}

UCL Center for Nephrology, Royal Free Campus,

University College London Medical School,

Rowland Hill Street, London NW3 2PF, UK

e-mail: Andrew.davenport@ royalfree.nhs.uk

The incidence of acute kidney injury (AKI) during hospital admission continues to rise in the developed world [1]. Typically, AKI occurs in a multi-factorial setting, more commonly affecting the older patient, with a background of pre-existing chronic kidney disease (CKD), and may be a reflection of both underlying patient co-morbidities and the increasing number and complexity of therapeutic options now available as medical technology continually advances. Not only does the development of AKI increase in-hospital mortality, but it also lengthens hospital in-patient stay, with increased health-care costs. More recent studies have now shown that the survivors have reduced short-term survival following hospital discharge, but also an increased risk of developing progressive $\mathrm{CKD}$, which may subsequently require chronic dialysis treatment in the longer term [2].

It is therefore timely that Joannidis and colleagues [3] have performed an extensive literature search and using the GRADE scoring system $[4,5]$ have proposed a series of clinical guidelines designed to help prevent AKI and protect kidney function in patients in the intensive care unit (ICU). The purpose of clinical guidelines is to help clinicians provide the best evidence-based patient care, but they also aid governmental health care policy makers, health care providers and insurers, patients and medical litigation lawyers by providing a benchmark standard of practice [6]. In addition, clinical guidelines help identify gaps in evidence that can then direct researchers and medical scientific research funding agencies. To achieve their goal, clinical guidelines must meet three key quality standards: well conceived with a defined scope and purpose, systematic review of the relevant primary literature, with transparent search strategies, providing criteria for both study inclusion and exclusion, and finally careful and detailed assessment of the quality of evidence [7].

The authors defined the scope of their guidelines and thereby deliberately excluded AKI associated with transplantation, primary renal disease and hepatorenal failure. In addition, although not formerly excluded, they did not consider the potential role of raised intra-abdominal pressure, ventilatory practices, blood transfusion or nephrotoxic drugs in causing AKI, and also did not fully address the cardiorenal syndromes.

It is only relatively recently that there has been a consensus on the definition of AKI, initially proposed by the ADQI group [8], which was then further revised by the AKI network, to define the timeframe of "acute" [9]. Thus, any literature search would have reviewed many publications with widely differing definitions of AKI, and this would have been compounded in the ICU setting, where the majority of patients are started on renal replacement therapy to correct volume overload [10] and/or acidosis rather than for azotaemia. Ideally, any intervention that can prevent AKI or protect kidney function should be readily reproducible in prospective multicenter trials. As with any literature review, not all studies were primary randomized controlled clinical trials [11], and similarly only a minority were conducted specifically within the ICU setting, and so the question 
arises as to whether the results of studies undertaken outside the ICU are directly applicable to those patients within the ICU.

At times, the authors step outside their defined scope of prevention of AKI and protecting kidney function in the ICU by extending their guidelines to patients undergoing cardiac surgery. This may have been due to a lack of appropriate studies in the ICU setting. For example, in the section on vasodilators, Joannidis and colleagues make a weak recommendation by suggesting the prophylactic use of fenoldopam for cardiac surgery patients at risk of AKI. However, the authors need to consider whether their guideline recommendations may be taken out of context from their specific recommendation and become generalized to the ICU patient without the appropriate level of evidence. As a therapeutic intervention that may be useful in reducing the incidence of AKI, for example, during cardiac surgery, may not necessarily be equally effective for other causes of AKI, such as sepsis.

The authors stress the importance of appropriate fluid resuscitation prior to the administration of contrast nephropathy, and maintaining sodium driven diuresis, but also advocate the use of peri-procedural hemofiltration in patients with severe chronic kidney disease undergoing coronary intervention, based on a limited experience. Although again this may appear to have strayed outside their intensive care remit, they do not review the literature on the risk of radiocontrast-induced nephropathy [12], which is often multi-factorial, related to the total dose of contrast administered, the route of administration, the type of contrast agent (hyperosmolar, iso-osmolar or hypo-osmolar, and ionic charge), and time interval between examinations. There are guidelines published by the European Society of Urogenital Radiology, again designed to reduce the risk of contrast nephropathy [13]. It is therefore important that when specialist societies construct their own clinical practice guidelines that they are cognizant of prior publications from other specialist groups with overlapping clinical practices to provide consistency were possible rather than diversity.

Joannidis and colleagues should be congratulated for their timely efforts. They have undertaken an extensive review and critique of the currently available literature. However, their clinical practice guidelines could potentially have benefited from a more systematic evidencedbased approach with limited but clearly defined and focused clinical questions. Their review has highlighted several areas of clinical uncertainty because of the lack of appropriately powered primary studies, and this needs to be emphasized so that these gaps in medical knowledge can be filled by future adequately powered multi-center prospective studies.

\section{References}

1. Waikar SS, Liu KD, Chertow GM (2008) Diagnosis, epidemiology and outcomes of acute kidney injury. Clin J Am Soc Nephrol 3:844-861

2. Lo LJ, Go AS, Chertow GM, McCulloch CE, Fan D, Ordoñez JD, Hsu CY (2009) Dialysis-requiring acute renal failure increases the risk of progressive chronic kidney disease. Kidney Int [Epub ahead of print] PMID: 19641480

3. Joannidis M, Druml W, Forni L, Groeneveld J, Honore P, Oudemans-van Straaten H, Ronco C, Schetz M, Wittiez A (2009) Prevention of acute kidney injury and protection of renal function in the intensive care unit. Intensive Care Med. doi: 10.1007/s00134-009-1678-y

4. Guyatt GH, Oxman AD, Vist GE, Kunz R, Falck-Ytter Y, Alonso-Coello P, Schünemann HJ, GRADE Working Group (2008) GRADE: an emerging consensus on rating quality of evidence and strength of recommendations. BMJ 336:924-926
5. Guyatt HG, Oxman AD, Kunz R, Vist GE, Falck-Ytter Y, The AGREE Collaboration (2003) Development and validation of an international appraisal instrument for assessing the quality of clinical practice guidelines: the AGREE project. Qual Saf Health Care 12:18-23

6. Liu B, Finfer S (2009) Intravenous fluids in adults undergoing surgery. BMJ 338:3-4. doi:10.1136/bmj.b2418

7. Guyatt GH, Oxman AD, Kunz R, Vist GE, Falck-Ytter Y, Schünemann HJ, GRADE Working Group (2008) What is "quality of evidence" and why is it important to clinicians? BMJ 336: 995-998

8. Bellomo R, Ronco C, Kellum JA, Mehta RL, Palevsky P, Acute Dialysis Quality Initiative Workgroup (2004) Acute renal failure-definition, outcome measures, animal models, fluid therapy and information technology needs: the Second International Consensus Conference of the Acute Dialysis Quality Initiative (ADQI) Group. Crit Care 8:R204-R212
9. Kellum JA, Bellomo R, Ronco C (2008) Definition and classification of acute kidney injury. Nephron Clin Pract 109:c182-c187

10. Moher D, Liberati A, Tetzlaff J, Altman DG, PRISMA Group (2009) Preferred reporting items for systematic reviews and meta-analyses: the PRISMA statement. BMJ 339:b2535. doi: 10.1136/bmj.b2535

11. Gibney N, Cerda J, Davenport A, Ramirez J, Singbartl K, Leblanc M, Ronco C (2008) Volume management by renal replacement therapy in acute kidney injury. Int $\mathbf{J}$ Artif Organs 31:145-155

12. Mehran R, Aymong ED, Nikolsky E, Lasic Z, Iakovou I, Fahy M, Mintz GS, Lansky AJ, Moses JW, Stone GW, Leon MB, Dangas G (2004) A simple risk score for prediction of contrastinduced nephropathy after percutaneous coronary intervention: development and initial validation. J Am Coll Cardiol 44:1393-1399

13. Thomsen HS, Morcos SK, ESUR (2006) ESUR guidelines on contrast media. Abdom Imaging 31:131-140 